\title{
Effect of restrictions on prescribing patterns for dextropropoxyphene
}

\author{
GILLIAN M SHENFIELD, A N JONES, J W PATERSON
}

\section{Summary and conclusions}

Prescribing of compound analgesics containing dextropropoxyphene was limited to consultants only in a teaching hospital. Inpatient prescribing (mainly by junior staff) fell immediately to very low levels but outpatient prescribing (by consultants) fell more slowly to about one-third of the original level, suggesting that patients and doctors find dextropropoxyphene compounds useful. Prescriptions for paracetamol increased but so did those for other compound analgesics, particularly those containing high doses of codeine, indicating a belief that compound analgesics have a role in treatment. Restrictions may produce unexpected results and monitoring is essential, but the method of audit used by pharmacies is not suitable for detailed analysis.

\section{Introduction}

Dextropropoxyphene, structurally related to the narcotic analgesic methadone, has become one of the most popular analgesics in the world, especially in combination with paracetamol. Recently its widespread use has caused concern. ${ }^{1}$

Reports from Britain, ${ }^{2}{ }^{3}$ the United States, ${ }^{4-6}$ and Denmark ${ }^{7}$ have shown that overdose of dextropropoxyphene can rapidly

Department of Pharmacology, University of Western Australia, Nedlands, Western Australia 6009

J W PATERSON, FRCP, FRACP, professor of clinical pharmacology

GILLIAN M SHENFIELD, DM, MRCP, senior lecturer in clinical pharmacology

Pharmacy, Sir Charles Gairdner Hospital, Nedlands, Western Australia 6009

A N JONES, FPS, chief pharmacist cause death from respiratory failure. In addition the paracetamol in combined preparations may cause death from hepatic failure, - and in Britain, between 1970 and 1974, 28\% of deaths from paracetamol poisoning were due to a dextropropoxyphene/paracetamol combination. ${ }^{8}$ The toxicity of dextropropoxyphene may also be enhanced by alcohol, ${ }^{6}{ }^{7910}$ and death has been reported from ingestion of only 15 tablets in combination with alcohol. ${ }^{3}$ There is some evidence that dextropropoxyphene has addictive properties. ${ }^{810-14}$

Formal clinical trials suggest that it has low potency as an analgesic. Fifteen double-blind trials showed that codeine in lower or equal doses produced analgesia equal to or greater than dextropropoxyphene, and seven studies showed that aspirin and caffeine in various doses were of equal or greater efficacy..$^{15}$ In nine studies dextropropoxyphene was more effective than placebo but in another seven it was not. ${ }^{15} \mathrm{~A}$ later study ${ }^{16}$ found that it had less analgesic effect than aspirin or paracetamol alone. Despite this the combination of dextropropoxyphene and paracetamol remains extremely popular.

Australia is no exception to world trends, and "Digesic" (dextropropoxyphene hydrochloride $32.5 \mathrm{mg}$ and paracetamol $325 \mathrm{mg}$, Dista) is one of the most widely prescribed analgesics. For the reasons outlined above, on 1 March 1978 prescribing restrictions were introduced in our 517-bed teaching hospital. From that date combination products containing dextropropoxyphene could be prescribed only by consultants. We describe the results of these restrictions.

\section{Methods}

The pharmacy keeps records of numbers of tablets purchased in any given period. These figures were collected for the nine-month period before and after the introduction of restrictions for the following commonly prescribed analgesic tablets: dextropropoxyphene hydrochloride $32.5 \mathrm{mg} /$ paracetamol $325 \mathrm{mg}$ (Digesic); dextropropoxyphene napsylate $100 \mathrm{mg} \equiv 65 \mathrm{mg}$ hydrochloride (Doloxene); paracetamol 
$500 \mathrm{mg}$; soluble aspirin $300 \mathrm{mg}$; aspirin $300 \mathrm{mg} /$ codeine $8 \mathrm{mg}$ (Aspalgin); paracetamol $500 \mathrm{mg} /$ codeine $8 \mathrm{mg}$ (Panadeine); and aspirin $225 \mathrm{mg} /$ paracetamol $150 \mathrm{mg} /$ codeine $30 \mathrm{mg}$ (Codral Forte). The actual numbers of tablets prescribed were not available, but note was made of the quantities of Digesic supplied to outpatients (90000 patients a year) and inpatients (17000 patients a year).

\section{Results}

The figure shows the numbers of tablets purchased before and after restrictions, and table I shows the individual tablets expressed as percentage of total analgesics purchased. Table II shows total outpatient and inpatient supplies of Digesic for the nine months before and after restrictions.

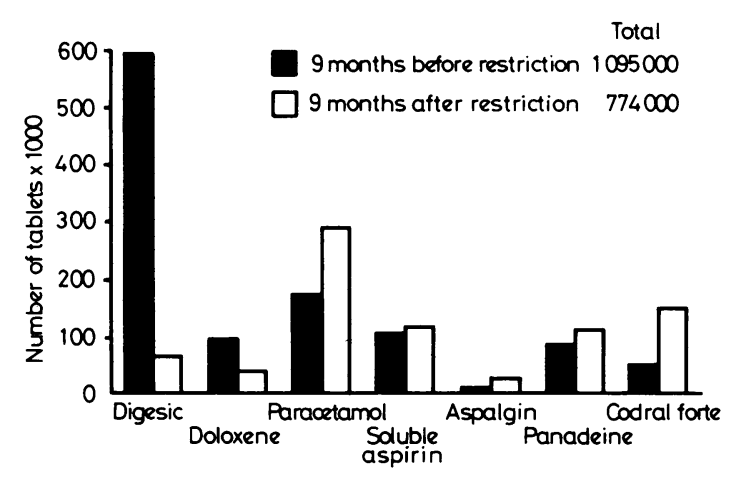

Number of tablets purchased before and after restrictions.

TABLE I-Tablets expressed as percentage of total analgesics purchased

\begin{tabular}{|c|c|c|}
\hline & Before restriction & After restriction \\
\hline $\begin{array}{l}\text { Dextropropoxyphene hydrochloride/ } \\
\text { paracetamol (Digesic) }\end{array}$ & $54 \cdot 8$ & $8 \cdot 4$ \\
\hline $\begin{array}{l}\text { Dextropropoxyphenenapsylate } \\
\text { hydrochloride (Doloxene) }\end{array}$ & 8.7 & 4.5 \\
\hline 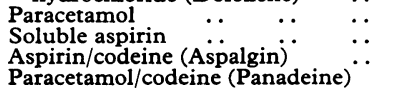 & $\begin{array}{r}15 \cdot 5 \\
9 \cdot 6 \\
1 \cdot 0 \\
6 \cdot 8\end{array}$ & $\begin{array}{r}38 \cdot 5 \\
14 \cdot 9 \\
2 \cdot 5 \\
14 \cdot 1\end{array}$ \\
\hline Aspirin/paracetamol/codeine & & \\
\hline (Codral Forte) & 3.6 & $18 \cdot 1$ \\
\hline
\end{tabular}

TABLE II-Number of tablets of Digesic supplied in hospital

\begin{tabular}{lcc}
\hline & Outpatients & Inpatients \\
\hline & Before restrictions imposed & \\
July-September 1977 & 150000 & 40000 \\
October-December 1977 & 190000 & 52000 \\
January-March 1978 & 110000 & 36000 \\
& After restrictions imposed & \\
April-June 1978 & 75000 & $<1000$ \\
July-September 1978 & 25000 & $<1000$ \\
October-December 1978 & 45000 & $<1000$ \\
\hline
\end{tabular}

The total number of analgesic tablets purchased over a nine-month period fell from 1.095 million to 0.774 million.

The use of Digesic in inpatients fell dramatically, but there was a slower decline in outpatient use. Prescribing of paracetamol increased by about half but that of soluble aspirin did not change. The use of compound analgesics, particularly Codral Forte, increased and since Codral Forte is very expensive the total cost of drugs fell proportionately less than the total number purchased-from $A \$ 13375$ to A $\$ 11525$ (table III).

Some problems arose from using purchasing and supply figures to estimate drug usage. Tables II and III show that a total of 578000 Digesic tablets were supplied before restrictions to outpatients and inpatients combined, but the total number of tablets purchased in the relevant period was 600000 . Similarly, after the restrictions 148000 tablets were supplied to both outpatients and inpatients and yet only
65000 were purchased. Thus a greater or lesser effect of the prescribing restriction could be deduced depending whether purchase data or supply data were used.

The purchasing figure for a further nine months from January to September 1979, during which restrictions persisted, were therefore examined (table III). They showed that the total number of tablets had increased again from 774000 to 854000 . Accompanying this was a rise in drug costs for analgesics, the new nine-month total being A $\$ 13$ 966. The reduction in amounts of Digesic and Doloxene purchased was largely balanced by increases in the amounts of paracetamol (Panadeine) and Codral Forte (table III)

TABLE III-Analgesic purchases over three nine-month periods

\begin{tabular}{|c|c|c|c|}
\hline & July $1977-$ Mar 1978 & April-Dec 1978 & Jan-Sep 1979 \\
\hline $\begin{array}{lll}\text { Overall total } & \ldots & \ldots \\
\text { Total cost } & \ldots & .\end{array}$ & $\begin{array}{r}1095000 \\
\$ 13375\end{array}$ & $\begin{array}{l}774000 \\
\$ 11525\end{array}$ & $\begin{array}{l}854000 \\
\$ 13966\end{array}$ \\
\hline $\begin{array}{l}\text { hydrochloride/paracetamol } \\
\text { (Digesic) }\end{array}$ & 600000 & 65000 & 150000 \\
\hline $\begin{array}{l}\text { Dextropropoxyphene- } \\
\text { napsylate/hydrochloride }\end{array}$ & & & \\
\hline $\begin{array}{lll}\text { (Doloxene) } & \cdots & \cdots \\
\text { Paracetamol } & \cdots & \cdots \\
\text { Paracetamol/codeine } & \end{array}$ & $\begin{array}{r}95000 \\
169000\end{array}$ & $\begin{array}{r}48000 \\
286000\end{array}$ & $\begin{array}{r}48000 \\
258000\end{array}$ \\
\hline $\begin{array}{l}\text { Paracetamol/codeine } \\
\text { (Panadeine) } \\
\text { Aspirin/paracetamol/ }\end{array} \quad \cdots$ & 74000 & 108000 & 120000 \\
\hline codeine (Codral Forte) & 40000 & 140000 & 175000 \\
\hline
\end{tabular}

\section{Discussion}

These results indicate that restricting the prescribing of a particular drug to consultants may have a substantial effect on prescribing patterns. The changes observed, however, raise important questions about the reasons for prescribing a particular drug, the wisdom of imposing restrictions, the importance of monitoring changes, and the methods of assessment to be used.

Our data are based on numbers of tablets purchased, since this is how our pharmacy does its auditing; and even had there been large stocks of Digesic at the time restrictions were imposed the figures for the third nine-month period we monitored suggest that there had been a true drop in the amount prescribed. Some outpatients, however, finding that they were not being given Digesic at the hospital, may have obtained prescriptions from their general practitioners.

Departments of pharmacy normally audit drug usage in terms of money spent and the acquisition of drugs. Inventory control centres on compliance with audit requirements rather than establishing an active record of the dispersement of drugs for ward units or doctors, and changes in drug usage cannot be identified quickly and accurately. We had not been fully aware of this difficulty before performing the present analysis.

Figures were available for the supply of Digesic to inpatient and outpatient departments. Inpatient prescribing of Digesic, predominately by junior staff, fell immediately. Of more interest is the lesser decline in outpatient, predominately consultant, prescribing. This suggests that some patients and experienced doctors believe that Digesic is a useful drug not readily substituted by any other product. Since the evidence for its analgesic properties is limited, its central effects may possibly be responsible for its popularity. Miller" ${ }^{15}$ stated "it appears that factors other than intrinsic therapeutic value are responsible for the commercial success of propoxyphene." Digesic is marketed as an attractive, compact, oblong white tablet that is easily swallowed. In Australia, in 1978-9, prescriptions were written on pharmaceutical benefits for 2346840 tablets of Digesic. Prescribing numbers for another preparation (Capadex) with identical constituents but marketed as a green and yellow capsule were only 244820 . The popularity of Digesic may therefore be related to expert marketing techniques.

Our findings also indicate a definite tendency to prescribe compound analgesics. We were greatly concerned to see that a compound containing $30 \mathrm{mg}$ of codeine phosphate (and pre- 
scribed two at a time) had become the compound analgesic of first choice. It is arguable that this could do more harm than the dextropropoxyphene it has replaced since codeine is well known to cause constipation, and this may be particularly dangerous in surgical wards. Of special concern is that this tendency to use the compound analgesics, in particular Codral Forte, became even more pronounced with longer follow-up.

We achieved our aim of reducing the use of Digesic within the hospital but created other problems. Our results show that prescribing restrictions are not the answer to the misuse and overuse of drugs. If they are introduced they should be carefully monitored by methods more subtle than the hospital pharmacy audit. At best they will only provide a short-term solution, and only by a continuous programme of active education of medical students and practising doctors will prescribing habits be improved.

\section{References}

${ }^{1}$ Breckenridge A. Dextropropoxyphene-a cautionary note. Prescribers' fournal 1978;18:49-50.

${ }^{2}$ Carson DJL, Carson ED. Dextropropoxyphene poisoning. $\mathrm{Br} \mathrm{Med} \mathfrak{f}$ 1976 ;ii:105-6.
${ }^{3}$ Whittington RM. Dextropropoxyphene (Distalgesic) overdosage in the West Midlands. Br Med f 1977; ;i:172-3.

${ }^{4}$ McBay AJ, Hudson P. Propoxyphene-overdose deaths. fAMA $1975 ; 233$ : 1257.

${ }^{5}$ Dougherty RJ. Propoxyphene-overdose deaths. $\mathcal{1} A M A$ 1976;235:1716.

${ }^{6}$ Bennett IF. Misuse of propoxyphene. FAMA 1976;235:1686.

${ }^{7}$ Christensen $\mathrm{H}$. Dodelige forgiftninger med dexstropropoksifen. Ugeskr Laeger 1975;137:2571-6.

${ }^{8}$ Vale JA, Volans GN, Crome P, Widdop B. Dextropropoxyphene poisoning. Br Med $\mathcal{F} 1976$;ii :424.

${ }^{9}$ Sturmer WQ, Garriott JC. Deaths involving propoxyphene. A study of 41 cases over a two-year period. $\mathcal{F} A M A \quad 1973 ; 223: 1125-30$.

10 Tennant FS, Preble MR, Groesbeck CJ, Banks NI. Drug abuse among American soldiers in West Germany. Milit Med 1972;132:191-4.

11 Fraser HF, Isbell $\mathrm{H}$. Pharmacology and addiction liability of dl- and d-propoxyphene. Bull Narc 1960;12:9-14.

${ }^{12}$ Claghorn JL, Schoolar JC. Propoxyphene hydrochloride, a drug of abuse. IAMA $1966 ; 196: 137-9$.

${ }^{13}$ Elson A, Domino EF. Dextropropoxyphene addiction. Observations of a case. $\mathcal{F} A M A$ 1963; 183:186-9.

${ }^{14}$ Tennant FS. Complications of propoxyphene abuse. Arch Intern Med 1973;132:191-4.

15 Miller RR, Feingold A, Paxinos J. Propoxyphene hydrochloride. A critical review. FAMA 1970;213:996-1006.

${ }^{16}$ Moertel CG, Ahmann DL, Taylor WF, Schwertau N. A comparative evaluation of marketed analgesic drugs. $N$ Engl $\mathcal{F}$ Med $1972 ; 286: 813-5$.

(Accepted 21 fuly 1980)

\title{
Hospital Topics
}

\section{Hospital work load produced by breast-cancer screening programme run by trained non-medical staff}

\author{
W D GEORGE, R A SELLWOOD, D A ASBURY, G HARTLEY
}

\section{Summary and conclusions}

In a feasibility study of mass population screening for breast cancer by annual clinical examination and mammography the findings of non-medical staff (nurses and radiographers) were used to estimate the hospital work load generated by such a programme. Among 2490 women who attended for the first time by invitation the rate of referral for a surgical opinion based on the findings of the non-medical staff was $7.9 \%$ and the biopsy rate $2.5 \%$. In the second and third years referral rates fell to $4 \cdot 3 \%$ and $2.7 \%$ respectively and the biopsy rates to $1 \cdot 1 \%$ and $1 \cdot 4 \%$.

The rates of referral and biopsy among 1203 women who referred themselves for screening were higher, but many self-referred women were symptomatic; those without symptoms had rates of referral and biopsy similar to those of the invited women.

Extrapolation of these findings to a population of

Department of Surgery, Royal Liverpool Hospital, Liverpool L7
8XP

W D GEORGE, MS, FRCS, senior lecturer

University Hospital of South Manchester, Manchester M20 8LR R A SELLWOOD, CHM, FRCS, professor of surgery

D A ASBURY, MB, FRCR, consultant radiologist

G HARTLEY, MB, FRCR, consultant radiologist
200000 in a typical health district showed that the hospital work load would be high in the first year of screening with 44 outpatient referrals per week and 14 biopsies. By the third year, however, only seven referrals and four biopsies a week could be expected. The work load would be reduced by a third if screening were confined to women over the age of 50 .

\section{Introduction}

The results of previous studies suggest that screening for cancer of the breast by annual clinical examination and mammography leads to detection of the disease at an early stage and consequently to improved survival. ${ }^{1}$

With present resources of medical manpower it would be impossible to offer a screening service to all women at risk unless examinations were carried out by trained non-medical staff. Such a service would require access to a hospital outpatient clinic to which patients with abnormalities could be referred for consultation and treatment. This might increase the surgical work load significantly and the size of the increase might be a major factor in determining the feasibility of providing a screening service.

In previous studies the rate of biopsy has ranged from $0.38 \%$ to $9.8 \%{ }^{3}$ and the rate of detection of cancer from 1.5 per $1000^{2}$ to $24 \cdot 6$ per $1000 .{ }^{4}$ Our aim was to evaluate the surgical work load produced by a screening service run by non-medical staff in terms of the rates of referral for consultation and biopsy. 